\title{
Comparing the duration of spinal anesthesia with bupivacaine between drug-dependent and non-dependent patients
}

\author{
Faranak Beirami ${ }^{1}$, Masoum Khoshfetrat ${ }^{2},{ }^{*}$, Hadi Khosravi $^{3}$, Aliakbar Keykha ${ }^{4}$
}

${ }^{1} \mathrm{MD}$, Department of Anesthesiology and critical Care, Khatamolanbia Hospital, Zahedan University of Medical Sciences, Zahedan, Iran

${ }^{2} M D$, FCCM, Department of Anesthesiology and critical Care, Khatamolanbia Hospital, Zahedan University of Medical Sciences, Zahedan, Iran

${ }^{3} \mathrm{MD}$, Anesthesiology and Critical Care Department, Zabol University of Medical Sciences, Zabol, Iran

${ }^{4} \mathrm{MSc}$ in Critical Care Nursing, Community Nursing Research Center, Zahedan University of Medical Sciences, Zahedan, Iran

\section{Correspondence}

Masoum Khoshfetrat, MD, FCCM Department of Anesthesiology and critical Care, Khatamolanbia Hospital, Zahedan University of Medical Sciences, Zahedan, Iran

Email: Drkhoshfetrat@yahoo.com

History

- Received: 04 August 2018

- Accepted: 30 September 2018

- Published: 15 October 2018

DOI :

https://doi.org/10.15419/bmrat.v5i10.486

\section{Check for updates}

\section{Copyright}

( ) Biomedpress. This is an openaccess article distributed under the terms of the Creative Commons Attribution 4.0 International license.

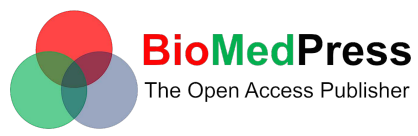

\begin{abstract}
Background: Drug abusers have much lower pain threshold, in a way that the duration of the effect of anesthesia on controlling their pain is still not fully known. Therefore, this study aimed to compare the duration of spinal anesthesia induced with bupivacaine between drug-dependent and non-dependent individuals. Methods: This quasi-experimental study was conducted on two 60-member groups consisting of drug-dependent and non-dependent patients undergoing lowerlimb orthopedic surgery. Patients were selected via simple convenience sampling and underwent a similar procedure of spinal anesthesia using the same needle and medicine by an anesthesiologist, who was unaware of the patients' placement in the study groups. After surgery, the duration of patients' anesthesia was correspondingly measured in both groups and compared using the independent t-test. Results: In this research study, no significant difference was observed between the groups in terms of age and gender. The mean duration of opium abuse in the drug-dependent patient group was reported to be $7.5 \pm 1.3$ years. In addition, the duration of spinal anesthesia in the drug-dependent patient group was shorter, compared to the non-dependent group ( $P=0.0001)$. Conclusion: According to the results of the study, intrathecal bupivacaine is not a durable anesthesia, for performing surgeries that might last more than an hour, in drug-dependent patients.

Key words: Bupivacaine, Drug-Dependent Individuals, Spinal Anesthesia
\end{abstract}

\section{INTRODUCTION}

Long-term drug abuse can result in increased drug dose to achieve analgesic effects. This process is called drug tolerance syndrome and its mechanism is not completely understood ${ }^{1,2}$. However, some hypotheses have been put forth explaining that the shape and function of receptors are likely to change as the drug concentration varies ${ }^{2,3}$. Considering legal limitations and social stigma, no accurate statistics on drug addiction have been reported in Iran. Nonetheless, inhalant abuse is the most common method of drug abuse in this country ${ }^{4,5}$. A shorter duration of spinal anesthesia was observed in chronic drug abusers, compared to non-dependent individuals, as reported by Dabbagh and colleagues; the researchers suggested comparing the levels of spinal anesthesia between the two groups in future studies ${ }^{6}$. While local anesthesia with bupivacaine acts through blocking sodium channels ${ }^{7}$, drugs exert their analgesic effects via $\mu$ receptors ${ }^{8}$.

There is similar mild respiratory acidosis among drug abusers. These individuals experience hypoventilation since acidosis may cause hydrogen $(\mathrm{H}+)$ entry into cerebrospinal fluid, subsequently decreasing the impact of anesthetics. These observations strongly suggest that there is a resistance to local anesthesia among drug-dependent individuals. Nevertheless, this hypothesis can be challenging to prove and further studies are required in this regard ${ }^{9,10}$. With this background in mind, the aim of this study was to compare the duration of spinal anesthesia with bupivacaine between drug-dependent and non-dependent patients.

\section{METHODS}

\section{Study Design and Ethical principles}

This quasi-experimental study was conducted on 120 patients referred to Khatam al-Anbiya Hospital in Zahedan, Iran to undergo lower-limb orthopedic surgery. The research was approved by the ViceChancellor's Office for Research and the Ethics Committee of Zahedan University of Medical Sciences. In addition, an informed consent was obtained from all participants.

\section{Patients and Sample Size}

The subjects were selected via simple convenience sampling. In this regard, all candidates for lowerlimb orthopedic surgery were enrolled in the study after meeting the inclusion criteria. Following that, the 
participants were divided into two 60-member groups of drug-dependent and non-dependent patients, in accordance with their history of drug abuse. Similarly, the sample size was estimated at 120 with reference to the relevant literature and based on the sample size calculation formula ${ }^{6}$.

\section{Inclusion and Exclusion Criteria}

The inclusion criteria included the age range of 20 50 years, possibility of using spinal anesthesia for the person, lack of coagulation disorders, no history of cardiovascular diseases, no diabetes, no diseases leading to neuropathy, no simultaneous addiction to nonopioids, lack of backbone disorders, no head trauma with high intracranial pressure, fracture of a lower limb, and patient's willingness to participate in the study. The exclusion criteria were lack of willingness to cooperate with the researcher, failure of spinal anesthesia and the need to have general anesthesia, feeling pain during the surgery, and the need to inject narcotics during the surgery.

\section{Interventions}

One day before the surgery, an anesthesiologist (the researcher) visited all patients and cardiovascular counseling, along with echocardiography, was conducted for all of patients after the visit. To alleviate pain in the drug-dependent patients prior to surgery, they were allowed to use their typical narcotics with their routine methods. In addition, $5 \mathrm{mg}$ of morphine was injected intramuscularly in the gluteal muscle if the pain was persistent. It should be noted that just $5 \mathrm{mg}$ of intramuscular morphine was injected into the non-dependent group, and only in the presence of pain. Since patients must fast for 8 hours before to surgery (NPO: nil per os/nothing by mouth), the infusion of $10 \mathrm{cc} / \mathrm{kg}$ of dextrose saline serum was started from the beginning of NPO and continued until the onset of the surgery. At the beginning of the surgery, the infusion of $10 \mathrm{cc} / \mathrm{kg}$ of serum ringer was initiated through the peripheral veins, followed by pulse oximetry screening and cardiac monitoring. After that, $4 \mathrm{cc}$ of $0.5 \%$ bupivacaine $(20 \mathrm{mg})$ was injected by needle (No. 25) between vertebrae L3-L4 in the subarachnoid space under sterilized conditions in a sitting position by an anesthesiologist, who was unaware of the patients' placement in the study groups. In the next stage, the participants were put in the dorsal recumbent position and were intravenously administered with $2 \mathrm{mg}$ of midazolam for sedation. In addition, mask oxygen therapy was performed at 6
$\mathrm{L} / \mathrm{min}$. After 5 minutes, the pinprick test was performed to confirm the effectiveness of spinal anesthesia. The given test was repeated every 10 minutes during the surgery. If the anesthesia was ineffective at any stage of the test, general anesthesia was applied and the patients were excluded from the study. However, if the anesthesia was effective, the patients' surgery was conducted by an orthopedist, who was unaware of the patients' placement in the study groups. Following that, the duration of the patients' anesthesia after the surgery, along with the demographic characteristics and history of drug abuse, were recorded for each patient in pre-designed forms.

\section{Statistical Analysis}

Data analysis was performed using the statistics program SPSS (version 24), with descriptive statistics, Chi-square test, and independent t-test.

\section{RESULTS}

In this research study, $72(60 \%)$ patients were male and $48(40 \%)$ participants were female. According to the results, no significant difference was observed between the study groups in terms of gender, considering the results of the Chi-square $(\mathrm{P}=0.60)$. The mean age of the patients was $37.4 \pm 5.7$ years, wherein there were $16(13.3 \%), 69(57.5 \%)$, and $35(29.2 \%)$ individuals in the age groups of 20-30, 30-40, and 40-50 years, respectively. Moreover, no significant difference was observed in the mean age of the study groups $(\mathrm{P}=0.863)$. On the other hand, the mean duration of drug abuse in the drug-dependent group was reported to be $7.5 \pm 1.3$ years. Furthermore, $44(73.3 \%)$ and $16(26.7 \%)$ of the participants had a history of drug abuse in inhalant and oral forms, respectively. Comparison of the spinal anesthesia duration between the two groups indicated a shorter period in the drugdependent patient group, as compared to the other patient group (non-dependent). In addition, the effect of spinal anesthesia in these patients was eliminated earlier, and this difference was statistically significant (Table 1).

From comparison of results based on the type of drug intake (oral versus inhalant), it was demonstrated that in inhalant abusers, spinal anesthesia was higher, as compared to oral drug users. While there was a slight difference in the mean duration, it was statistically significant (Table 2).

\section{DISCUSSION}

The results of this study showed that the duration of spinal anesthesia was significantly shorter in the drugdependent patients, compared to the non-dependent 
Table 1: Comparing spinal anesthesia with bupivacaine between drug-dependent and non-dependent patients (in minutes) using independent t-test results

\begin{tabular}{|c|c|c|c|}
\hline $\begin{array}{c}\text { Group } \\
\text { Variable }\end{array}$ & Drug-dependent & Non-dependent & P-value \\
\hline $\begin{array}{l}\text { Duration of spinal anesthesia with } \\
\text { bupivacaine }\end{array}$ & $\begin{array}{l}\quad 91.7 \pm 14.8 \\
\text { (standard deviation } \pm \text { mean) }\end{array}$ & $\begin{array}{c}132.5 \pm 18.1 \\
\text { (standard deviation } \pm \text { mean) }\end{array}$ & 0.0001 \\
\hline
\end{tabular}

Table 2: Comparing spinal anesthesia with bupivacaine based on opioid drug use methods (in minutes) using independent $t$-test results

\begin{tabular}{|c|c|c|c|}
\hline $\begin{array}{c}\text { Group } \\
\text { Variable }\end{array}$ & $\begin{array}{l}\text { Inhalant } \\
\mathrm{n}=44\end{array}$ & $\begin{array}{c}\text { Oral } \\
n=16\end{array}$ & P-value \\
\hline $\begin{array}{l}\text { Duration of spinal anesthesia with } \\
\text { bupivacaine }\end{array}$ & $\begin{array}{l}\quad 92.8 \pm 12.6 \\
\text { (standard deviation } \pm \text { mean) }\end{array}$ & $\begin{array}{l}\quad 88.7 \pm 9.9 \\
\text { (standard deviation } \pm \text { mean) }\end{array}$ & 0.0001 \\
\hline
\end{tabular}

individuals. It should be noted that the effect of narcotic compounds on the body's pain system can be induced not only by conventional opioid receptors but by other numerous receptors in the central and peripheral nervous systems, which can be significantly affected by such compositions ${ }^{11}$. Among chronic drug abusers, the responses of opioid receptors to painful stimuli fluctuate. In this respect, frequent substance abuse can lead to a connection between opioids and receptors, thereby preventing the proper transcription of DNA and production of nonnatural proteins, which can result in hyperalgesia and allodynia $^{1,12-15}$. Moreover, the immune response of such patients is altered and there is an increase in the ratio of pro-inflammatory interleukins to antiinflammatory interleukins.

These above factors suggest a decrease in the relative effect of anesthesia medications during surgery as well as the potential need for a higher dose of medicine to control the patients' pain and stress. As these have not been proven, further studies would be helpful in this regard ${ }^{16-19}$. In a study by Sadeghi et al., the duration of spinal anesthesia in drug-dependent and nondependent patients was measured. Sadeghi et al. divided the subjects into four groups. In the first group, consisting of non-dependent individuals, hyperbaric bupivacaine with $1 \mathrm{cc}$ of saline was injected; in the second group encompassing non-dependent patients, bupivacaine with sufentanil was injected; in the third group containing drug-dependent subjects, placebo and intrathecal bupivacaine were injected; and finally in the fourth group (the drug-dependent patients), sufentanil and intrathecal bupivacaine were injected. After that, the start time and duration of anesthesia in the study groups were measured and compared. According to the results, there was a shorter duration of spinal anesthesia in the third group, compared to the other study groups. It was concluded that adding $5 \mathrm{mg}$ of intrathecal sufentanil to the patients' local anesthesia could make the duration of their spinal anesthesia equivalent to that of non-dependent patients ${ }^{4}$.

Despite the difference in the type of drug used in the aforementioned and present studies, our findings are in agreement with the results obtained by Sadeghi and colleagues ${ }^{4}$. In line with the results of the present study, Dabbagh et al. (2007) reported that the duration of spinal anesthesia in opioid abusers and control groups were $86.6 \pm 15.7$ and $162 \pm 22.1$ minutes, respectively, and that this difference was statistically significant. This study also indicated that the duration of spinal anesthesia with bupivacaine was shorter in the groups of opioid abusers, which was probably due to the cross-resistance between the anesthesia area and the opioid compounds in the spinal neurons ${ }^{6}$. In a research by Karbasy et al. (20), however, when the levels and duration of spinal anesthesia with bupivacaine in drug-dependent and non-dependent individuals were compared, a significantly longer duration of spinal anesthesia in drug-dependent patients and lower levels of spinal anesthesia were observed, as compared to non-dependent individuals.

One of the major drawbacks of the study herein was the lack of evaluation of the levels and duration of spinal anesthesia. Nevertheless, the obtained results confirmed that using bupivacaine might be insufficient for inducing anesthesia in drug-dependent individuals ${ }^{20}$. Furthermore, in a study by Hashemian et al. on drug-dependent and non-dependent patients with hand injury, it was reported that the drugdependent patients required higher doses of lidocaine for injury block. In addition, the results were indicative of a significantly longer starting time for these in- 
dividuals $^{21}$. Certainly, one should pay particular attention to the fact that in Iranian culture, it is a social disgrace to admit your addiction. Another major limitation of this study is the reliance of accurate data on self-reporting (especially about addiction). This impacts placement of patients in the correct group (drug-dependent versus non-dependent). For example, a patient may have an addiction to a drug but not find that addiction bothersome; thus, they may be placed wrongly in the non-dependent group as opposed to dependent group. It is also worth noting that patients' dissatisfaction with performing the addiction test for entering into the study was an unresolved issue, which might have contributed to the distortion of the final results.

\section{CONCLUSION}

According to the results of the study, there was a significantly shorter duration of spinal anesthesia in the drug-dependent individuals, compared to the nondependent subjects. Therefore, spinal anesthesia can only be used in short-term surgeries for drug dependent people. In general, it is recommended that general anesthesia be used for these patients in surgeries that may last more than an hour.

\section{COMPETING INTERESTS}

The authors declare that there is no conflict of interest regarding the publication of this article.

\section{FUNDING}

The study was financially supported by Zahedan University of Medical Sciences, Zahedan, Iran.

\section{AUTHORS' CONTRIBUTIONS}

Faranak Beirami: advising in development of research and revising this paper. Masoum Khoshfetrat: participating in the implementation of research and supervising the data collection and revising the paper. Hadi Khosravi: participating in the implementation of research and data collection. Aliakbar Keykha: Compiling and editing the paper. All authors reviewed, commented and approved the final version.

\section{ACKNOWLEDGMENTS}

This article was extracted from a thesis written by a resident of anesthesiology and critical care, approved and funded by Research and Technology Deputy of Zahedan University of Medical Sciences. Hereby, we extend our gratitude to the Research and Technology Deputy of the University. In addition, we would like to thank the staff and orthopedic surgery ward at the
Khatam-ol-Anbia Hospital of Zahedan for assisting us in this reseach.

\section{REFERENCES}

1. Ossipov MH, Lai J, King T, Vanderah TW, Porreca F. Underlying mechanisms of pronociceptive consequences of prolonged morphine exposure. Biopolymers. 2005;80:319-24. Available from: DOI:10.1002/bip.20254

2. Gardell LR, King T, Ossipov MH, Rice KC, Lai J, Vanderah TW. Opioid receptor-mediated hyperalgesia and antinociceptive tolerance induced by sustained opiate delivery. Neuroscience Letters. 2006;396:44-9. Available from: DOI:10.1016/j.neulet. 2005.11.009.

3. Szeto HH, Soong Y, Wu D, Qian X, Zhao GM. Endogenous opioid peptides contribute to antinociceptive potency of intrathecal [Dmt1]DALDA. The Journal of Pharmacology and Experimental Therapeutics. 2003;305:696-702. Available from: DOI:10.1124/jpet.102.048561.

4. Sadeghi M, Yekta RA, Azimaraghi O, Barzin G, Movafegh A. Evaluation of spinal anesthesia blockade time with $0.5 \%$ hy perbaric bupivacaine, with or without sufentanil, in chronic opioid users: a randomized clinical trial. Brazilian Journal of Anesthesiology. 2016;66:346-50. Available from: DOI:10 1016/j.bjane.2014.11.009.

5. Mokri A. Brief overview of the status of drug abuse in Iran 2002;.

6. Dabbagh A, Dahi-Taleghani M, Elyasi H, Vosoughian M, Malek $B$, Rajaei S. Duration of spinal anesthesia with bupivacaine in chronic opium abusers undergoing lower extremity orthopedic surgery. Archives of Iranian Medicine. 2007;10:316-20.

7. Wood JN, Boorman JP, Okuse K, Baker MD. Voltage-gated sodium channels and pain pathways. Journal of Neurobiology. 2004;61:55-71. Available from: DOI:10.1002/neu.20094.

8. Gomes I, Jordan BA, Gupta A, Trapaidze N, Nagy V, Devi LA. Heterodimerization of $\mu$ and $\delta$ opioid receptors: A role in opiate synergy. The Journal of Neuroscience : The Official Journal of the Society for Neuroscience. 2000;20:RC110. Available from: DOI:10.1523/JNEUROSCI.20-22-j0007.2000.

9. Kouzehgaran S, Saber-Tanha A. What Is the Main Reason for Reduction in Duration of Action of Local Anesthetics Used for Spinal Anesthesia in Opium Addicted Patients? Addiction \& Health. 2015;7:198.

10. Shook JE, Watkins WD, Camporesi EM. Differential roles of opioid receptors in respiration, respiratory disease, and opiateinduced respiratory depression. The American Review of Respiratory Disease. 1990;142:895-909. Available from: DOI 10.1164/ajrccm/142.4.895.

11. Bovill JG. Mechanisms of actions of opioids and non-steroidal anti-inflammatory drugs. European Journal of Anaesthesiology Supplement. 1997;15:9-15. Available from: Doi:10.1097/ 00003643-199705001-00003.

12. King T, Ossipov MH, Vanderah TW, Porreca F, Lai J. Is paradoxical pain induced by sustained opioid exposure an underlying mechanism of opioid antinociceptive tolerance? Neuro-Signals. 2005;14:194-205. Available from: Doi:10.1159/ 000087658.

13. Angst MS, Clark JD. Opioid-induced hyperalgesia: a qualitative systematic review. Anesthesiology. 2006;104:570-87. Available from: Doi:10.1097/00000542-200603000-00025.

14. $\mathrm{Xu} \mathrm{H}, \mathrm{XuT}, \mathrm{Ma} \mathrm{X}$, Jiang W. Involvement of neuronal TGF- $\beta$ activated kinase 1 in the development of tolerance to morphineinduced antinociception in rat spinal cord. British Journal of Pharmacology. 2015;172:2892-904. Available from: DOI: 10.1111/bph.13094.

15. Dogrul A, Bilsky EJ, Ossipov MH, Lai J, Porreca F. Spinal Ltype calcium channel blockade abolishes opioid-induced sensory hypersensitivity and antinociceptive tolerance. Anesthesia and Analgesia. 2005;101:1730-5. Available from: Doi: 10.1213/01.ane.0000184253.49849.b0. 
16. King T, Gardell LR, Wang R, Vardanyan A, Ossipov MH, Malan TP. Role of NK-1 neurotransmission in opioid-induced hyperalgesia. Pain. 2005;116:276-88. Available from: DOI:10.1016/ j.pain.2005.04.014.

17. Vera-Portocarrero LP, Zhang ET, King T, Ossipov MH, Vanderah TW, Lai J. Spinal NK-1 receptor expressing neurons mediate opioid-induced hyperalgesia and antinociceptive tolerance via activation of descending pathways. Pain. 2007;129:35-45. Available from: DOI:10.1016/j.pain.2006.09.033.

18. Xu ZZ, Kim YH, Bang S, Zhang Y, Berta T, Wang F. Inhibition of mechanical allodynia in neuropathic pain by TLR5-mediated A-fiber blockade. Nature Medicine. 2015;21:1326-31. Available from: DOI:10.1038/nm.3978.

19. Araldi D, Ferrari LF, Levine JD. Repeated mu-opioid exposure induces a novel form of the hyperalgesic priming model for transition to chronic pain. The Journal of Neuroscience : The Official Journal of the Society for Neuroscience. 2015;35:12502-17. Available from: Doi:10.1523/jneurosci. 1673-15.2015.

20. Karbasy SH, Derakhshan P. Effects of opium addiction on level of sensory block in spinal anesthesia with bupivacaine for lower abdomen and limb surgery: a case-control study. Anesthesia and Pain Medicine. 2014;4:e21571. Available from: DOI:10.5812/aapm.21571.

21. Hashemian AM, Omraninava A, Kakhki AD, Sharifi MD, Ahmad $\mathrm{K}$, Masoumi B. Effectiveness of local anesthesia with lidocaine in chronic opium abusers. Journal of Emergencies, Trauma and Shock. 2014;7:301-4. Available from: Doi:10.4103/09742700.142765 . 